Wärme- und Stoffübertragung 12 (1979) 83-87

Wäpme-unn Stoffiluentrangung

Thepme- and Fluid Dynamics

(C) by Springer-Verlag 1979

\title{
Laminar Natural Convection Over a Slender Vertical Frustum of a Cone
}

\author{
T.Y. Na and J.P. Chiou, Michigan U.S.A.
}

Abstract. The problem of laminar, natural convection flow over a slender frustum of a cone is treated in this paper. The governing differential equations are solved by a combination of quasi-linearization and finite-difference methods. Numerical solutions are obtained for $\mathrm{Pr}=0.7$ and for a range of values of the transverse curvature parameter. It is shown that the effect of transverse curvature is of great significance in such flows.

Laminare natürliche Konvektion an einem dünnen, senkrechten Kegelstumpf

Zusammenfassung. In diesem Bericht ist das Problem der laminaren natürlichen Konvektionsströmung an einem dünnen Kegelstumpf behandelt. Die maßgebliche Differentialgleichung ist durch eine Verbindung von Quasilinearisation und Differenzenverfahren gelöst. Eine numerische Lösung für Pr $=0.7$ wird für verschiedene Werte eines Krümmungsparameters angegeben. Es ist gezeigt, daß in solchen Strömungen dieser Krümmungsparameter eine große Bedeutung besitzt.

\section{Nomenclature}

f dependent variable, defined in Eq. (7)

g dependent variable, defined in $\mathrm{Eq} .(7)$

$g_{e} \quad$ gravitational acceleration

h heat transfer coefficient, or $\eta$-grid

$\mathrm{k}$ heat conductivity, or $\xi$-grid

L characteristic length

$\mathrm{Nu} \quad$ Nusselt number

Pr PrandtI number

$r$ radial distance from the axis of the cone

$\mathrm{R} \quad$ transverse curvature effect ratio, defined in Eq. (23)

Re Reynold number

$\mathrm{T}$ temperature

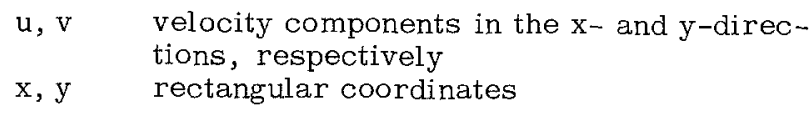

$\mathrm{x}, \mathrm{y}$

Greek letters

$\theta$ dimensionless temperature, defined in $\mathrm{Eq}$. (4)

$\beta \quad$ bulk modulus

$\alpha \quad$ cone angle

$\nu \quad$ dynamic viscosity

* stream function

$\xi, \eta \quad$ independent variable, defined in (7)

$\gamma$ transverse curvature parameter

\section{Introduction}

The problem of laminar natural convection flow over a vertical cone has been treated in the literature by many authors since 1953. Merk and Prins [1] found the similarity solution for the case of an isothermal cone. This case was extended by Hering and Grosh [2] to the case of non-isothermal cones where the wall temperature varies as $\mathrm{x}^{\mathrm{n}}$. Similarity solutions were obtained for a family of values of $n$ 's. Further analyses of this problem for low Prandtl numbers were made by Hering [3] and Sparrow and Guinle [4] and, for large Prandtl numbers, by Roy [5]. In all these works, however, the flows considered are similar and, as such, the governing differential equ- ations can be reduced to ordinary differential equations. Another limitation is that the cone angles under consideration are large so that the transverse curvature effects are negligible.

In this paper, we will consider the natural convection over a slender frustum of a cone (Fig.1). This analysis differs from previous works on this subject in three aspects. First, the flow is non-similar. Second, the transverse curvature effect has to be included since now the boundary layer thickness is of the same order-of-mangitude of the radius of the cone $[6,7]$. Third, a frustum of a cone (Fig.1), instead of a full cone, is considered. However, as $x_{0}$ approaches to zero, the flow will approach to the natural convection flow over a full cone. 


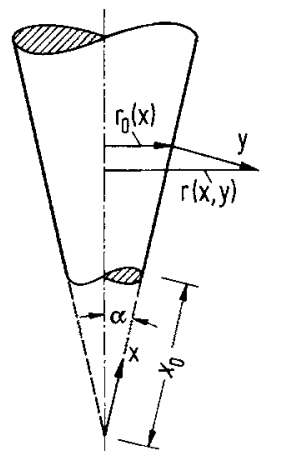

Fig.1. Coordinate system

The governing differential equations are first linearized by the quasilinearization method. The resulting equations are then solved by a finite-difference method outlined in detail in reference 8 .

\section{Analysis}

The governing differential equations for the solution of natural convection flow past a slender vertical frustum of a cone with constant wall temperature (Fig.1) can be written in terms of dimensionless quantities as:

$\frac{\partial(\overline{\mathrm{r}} \overline{\mathrm{u}})}{\partial \overline{\mathrm{x}}}+\frac{\partial(\overline{\mathrm{r}} \overline{\mathrm{v}})}{\partial \overline{\mathrm{y}}}=0$

$\overrightarrow{\mathrm{u}} \frac{\partial \overline{\mathrm{u}}}{\partial \overline{\mathrm{x}}}+\overline{\mathrm{v}} \frac{\partial \overline{\mathrm{u}}}{\partial \overline{\mathrm{y}}}=\frac{1}{\overline{\mathrm{r}}} \frac{\partial}{\partial \overline{\mathrm{y}}}\left\{\overline{\mathrm{r}} \frac{\partial \overline{\mathrm{u}}}{\partial \overline{\mathrm{y}}}\right\}+\theta$

$\overline{\mathrm{u}} \frac{\partial \theta}{\partial \overline{\mathrm{x}}}+\overline{\mathrm{v}} \frac{\partial \theta}{\partial \overline{\mathrm{y}}}=\frac{1}{\operatorname{Pr}} \frac{1}{\overline{\mathrm{r}}} \frac{\partial}{\partial \overline{\mathrm{y}}}\left(\overline{\mathrm{r}} \frac{\partial \theta}{\partial \overline{\mathrm{y}}}\right)$.

The boundary conditions are:

$\overline{\mathrm{y}}=0: \overline{\mathrm{u}}=0 ; \quad \overrightarrow{\mathrm{v}}=0 ; \quad \theta=1$

$\overline{\mathrm{y}}=\alpha: \overline{\mathrm{u}}=0 ; \quad \theta=0$.

The dimensionless quantities in Eqs. (1), (2) and (3) are related to their corresponding physical variables through the following definitions:

$\bar{x}=\frac{x-x_{0}}{L} ; \bar{y}=\frac{y}{L} \sqrt{R e_{L}} ; \bar{u}=\frac{u}{u_{c}} ; \bar{v}=\frac{v}{u_{c}} \sqrt{R e_{L}}$

$\frac{r_{0}(x)}{r_{0}}=\frac{\sqrt{R e_{L}}}{L} ; \quad \theta=\frac{T-T_{\propto}}{T_{w}-T_{\propto}} ; \quad \bar{r}=\frac{r}{L} \sqrt{R e_{L}}$
$\mathrm{u}_{\mathrm{c}}=\left[\mathrm{g}_{\Theta} \beta \cos \alpha\left(\mathrm{T}_{\mathrm{w}}-\mathrm{T}_{\propto}\right) \mathrm{L}\right]^{1 / 2}$

$R e_{L}=\frac{u_{C} L}{v}$

If the characteristic length, $L$, is chosen as the distance $\mathrm{x}_{0}$ (Fig.1), then the Reynolds number becomes:

$\operatorname{Re}_{L}=\frac{u_{c} x_{0}}{\nu}=\left\{\frac{g_{e} \beta \cos \alpha\left(T_{w}-T_{\propto}\right) x_{0}^{3}}{\nu^{2}}\right\}^{1 / 2}=G r_{0}^{1 / 2}$

where $\mathrm{Gr}_{\mathrm{x}_{0}}$ is the Grashof number based on $\mathrm{x}_{0}$.

Next, the following transformation will be introduced:

$\xi=\bar{x} ; \quad \eta=\frac{\bar{y}}{\bar{x}^{1 / 4}}$

$f(\xi, \eta)=\frac{\psi}{\bar{x}^{3 / 4} \bar{r}_{0}} ; g(\xi, \eta)=\theta$

where the stream function $\psi$ is defined by:

$\bar{r} \bar{u}=\frac{\partial \psi}{\partial \bar{y}} \quad$ and $\quad \bar{r} \bar{v}=-\frac{\partial \psi}{\partial \bar{x}}$

and, for cones,

$\mathbf{r}_{0}=\mathrm{x} \sin \alpha$.

Equations (1), (2) and (3) then become:

$\left(\frac{\overline{\mathrm{r}}_{0}}{\overline{\bar{r}}}\right)\left\{\left(\frac{\overline{\mathrm{r}}}{\overline{\mathrm{r}}_{0}}\right)\left[\left(\frac{\overline{\mathrm{r}}_{0}}{\overline{\bar{r}}}\right) \mathrm{f}^{\prime}\right]^{\prime}\right\}^{\prime}+\left(\frac{\overline{\mathrm{r}}_{0}}{\overline{\bar{r}}}\right)\left\{\left(\frac{\overline{\mathrm{r}}_{0}}{\overline{\bar{r}}}\right) \mathrm{f}^{\prime}\right\}^{\prime} \times$

$\times\left\{\frac{3+4 S}{4} f^{-}-\frac{1}{4} \eta f^{\prime}\right\}-\left(\frac{\bar{r}_{0}}{\bar{r}}\right)^{2} f^{\prime}\left\{\left(\frac{1+2 S}{2}-\frac{\bar{r}_{0}}{\bar{r}} S\right) f^{\prime}-\frac{1}{4} \eta f^{\prime \prime}\right\}+g$

$=\xi\left\{\left(\frac{\overline{\mathrm{r}}_{0}}{\overline{\mathrm{r}}}\right)^{2} \mathrm{f}^{\prime} \frac{\partial \mathrm{f}^{\prime}}{\partial \xi}-\left(\frac{\overline{\mathrm{r}}_{0}}{\overline{\bar{r}}}\right)\left[\left(\frac{\overline{\mathrm{r}}_{0}}{\overline{\mathrm{r}}}\right) \mathrm{f}^{\prime}\right]^{\prime} \frac{\partial \mathrm{f}}{\partial \xi}\right\}$

$\frac{1}{\operatorname{Pr}}\left\{\left(\frac{\bar{r}}{\bar{r}_{0}}\right) g^{\prime}\right\}^{\prime}+\frac{3+4 S}{4} f g^{\prime}=\xi\left(f^{\prime} \frac{\partial g}{\partial \xi}-g^{\prime} \frac{\partial f}{\partial \xi}\right)$

subject to the boundary conditions:

$\eta=0: \mathrm{f}(\xi, 0)=\mathrm{f}^{\prime}(\xi, 0)=0 ; \mathrm{g}(\xi, 0)=1$

$\eta=\alpha: f^{\prime}(\xi, \propto)=0 ; g(\xi, \alpha)=0$ 
where primes in Eqs. (10) and (11) represent differentiation with respect to $\eta$, and $S=\xi /(1+\xi)$.

The ratio $r / r_{0}$ represents the effect of transverse curvature. For cones with large cone angle, $r$ is very close to $r_{0}$ and the transverse curvature effects are negligible. For such flows, the ratio $\overrightarrow{\mathrm{r}} / \overline{\mathrm{r}}_{0}$ is taken to be 1. Equations (10) and (11) are similar and become:

$f^{\prime \prime \prime}+\frac{7}{4} f f^{\prime \prime}-\frac{1}{2}\left(f^{\prime}\right)^{2}+g=0$

$\frac{1}{\mathrm{Pr}} \mathrm{g}^{\prime \prime}+\frac{7}{4} \mathrm{f}^{\prime}=0$

which are the Equations given by Hering and Grosh [2].

For cones, we have

$r=r_{0}+y \cos \alpha$

$r_{0}=x \sin \alpha$.

In terms of the similarity variables defined in $\mathrm{Eq}$. (7), the ratio $\overline{\mathrm{r}} / \overline{\mathrm{r}}_{0}$ can therefore be written as:

$\frac{\bar{r}}{\bar{r}_{0}}=1+\gamma \frac{\xi^{1 / 4}}{1+\xi} \eta$

where the TVC (transverse curvature) parameter $\gamma$ is defined as:

$\gamma=\frac{\operatorname{Cot} \alpha}{\operatorname{Gr}_{\mathrm{x}_{0}}^{1 / 4}}$

Substituting $\overline{\mathrm{r}} / \overline{\mathrm{r}}_{0}$ from Eq. (14) into Eqs. (10) and (11), we get:

$$
\begin{aligned}
f^{\prime \prime \prime} & -\frac{\gamma^{*}}{()^{\prime \prime}}+\frac{\gamma^{*}{ }^{2}}{()^{2}} f^{\prime}+\frac{1}{()} \cdot\left\{\frac{3+4 S}{4} f^{\prime \prime}-\left[\frac{1+2 S}{2}-\frac{S}{(\zeta)}\right]\left(f^{\prime}\right)^{2}\right\} \\
& -\frac{\gamma^{*}}{()^{2}} f^{\prime}\left\{\frac{3+4 S}{4} f-\frac{1}{4} \eta^{\prime}\right\}+() g \\
& =\xi\left\{\frac{f^{\prime}}{(T)} \frac{\partial f^{\prime}}{\partial \xi}-\frac{() f^{\prime \prime}-\gamma^{*} f^{\prime}}{()^{2}} \frac{\partial f}{\partial \xi}\right\}
\end{aligned}
$$$$
g^{\prime \prime}+\frac{Y^{*}}{(T} g^{\prime}+\frac{3+4 S}{4} \frac{P r}{(\supset} f^{\prime}=\xi \frac{P r}{(T}\left\{f^{\prime} \frac{\partial g}{\partial \xi}-g^{\prime} \frac{\partial f}{\partial \xi}\right\}
$$

subject to the boundary conditions: $\eta=0: f(\xi, 0)=f^{\prime}(\xi, 0)=0 ; g(\xi, 0)=1$

$\eta=\propto: f^{\prime}(\xi, \propto)=0 ; g(\xi, \propto)=0$

where the notation "( )" in Eqs. (16) and (17) represents the two terms on the right-hand side of Eq. (14), and

$$
\gamma^{*}=\frac{\xi^{1 / 4}}{(1+\xi)} .
$$

\section{Numerical Solutions}

To solve Eqs. (16) and (17), they are first written as a first-order system. The derivatives are then approximated by centered-difference gradients and averages centered at the midpoints of the net rectangles defined by:

$$
\xi_{0}=0, \quad \xi_{n}=\xi_{n-1}+k_{n}, \quad n=1,2, \ldots, N
$$

$\eta_{0}=0, \eta_{j}=\eta_{j-1}+h_{j}, j=1,2, \ldots, J$

$\eta_{\mathrm{J}}=\eta_{\infty}$

as shown in Fig. 2. A non-uniform grid $h_{j}$ defined by

$h_{j}=K h_{j-1}$

where the ratio of adjacent intervals, $K$, is a constant. The distance from the surface to the $j$ th station is then given by:

$\eta_{j}=h_{j} \frac{K^{j}-1}{K-1}, \quad j=1,2, \ldots, J$.

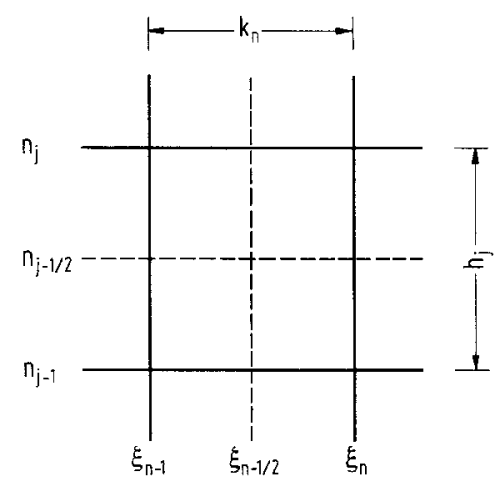

Fig.2. A typical grid point 
The $\xi$-direction grid $\mathrm{k}_{\mathrm{n}}$ is arbitrary. The linearization is achieved by the method of quasilinearization and the resulting system of algebraic equations are then solved by an efficient block-tridiagonal factorization technique. Details of the method of solution are identical to the one used in reference 8 and are therefore omitted here.

The rate of heat transfer from the cone to the fluid is characterized by the local Nusselt number defined by:

$\mathrm{Nu}_{\mathrm{x}}=\frac{\mathrm{hx}}{\mathrm{k}}$

where $\mathrm{h}$ is the local heat transfer coefficient defined by:

$-k\left(\frac{\partial T}{\partial y}\right)_{y=0}=h\left(T_{w}-T_{\alpha}\right)$. get :

In terms of the similarity variables and $\mathrm{Gr}_{x_{0}}$, we

$\left(\frac{\mathrm{Nu}_{\mathrm{x}}}{\mathrm{Gr}_{\mathrm{x}_{0}^{1 / 4}}^{1 / \mathrm{TVC}}}\right)=\left[-\mathrm{g}^{\prime}(0)\right]_{\mathrm{TVC}}$

where the subscript "TVC" means the effect of TVC is included. If the effect of TVC is not included in Eqs. (10) and (11) [i.e., Eqs. (12) and (13) are solved instead], a similar expression can be written as:

$\left(\frac{\mathrm{Nu}_{\mathrm{x}}}{\mathrm{Gr}_{\mathrm{x}_{0}}^{1 / 4}}\right)_{\text {NO-TVC }}=\left[-\mathrm{g}^{\prime}(0)\right]_{\mathrm{NO}-\mathrm{TVC}} \cdot$

It should be noted that if the TVC effects are neglected, $\left[-g^{\prime}(0)\right]$ is constant for a given value of Pr, as is seen from Eqs. (12) and (13). On the other hand, $\left[-g^{\prime}(0)\right]$ is a function of $\vec{x}$ for a given $\operatorname{Pr}$ if the effect of TVC is included. For this reason, we consider the ratio of the two expressions in Eqs. (21) and (22), namely,

$R=\frac{\left[-g^{\prime}(0)\right]_{\text {TVC }}}{\left[-g^{\prime}(0)\right]_{\text {NO-TVC }}}$.

If the TVC effect is negligible, the ratio $R$ will be equal to 1 . The ratio $R$ is greater or smaller
Table 1. R-vs $-\overrightarrow{\mathrm{x}}$ for various $\gamma^{\prime} \mathrm{s}(\operatorname{Pr}=0.7)$

\begin{tabular}{lllll}
\hline & \multicolumn{4}{c}{$\mathrm{R}$} \\
\cline { 2 - 5 } $\mathrm{x}$ & $\gamma=0.25$ & $\gamma=0.50$ & $\gamma=0.75$ & $\gamma=1.00$ \\
\hline 0.00 & 0.7829 & 0.7829 & 0.7829 & 0.7829 \\
0.25 & 0.9030 & 0.9785 & 1.0521 & 1.1240 \\
0.75 & 1.0082 & 1.1343 & 1.2530 & 1.3657 \\
1.75 & 1.0257 & 1.1226 & 1.2241 & 1.3019 \\
3.75 & 1.0335 & 1.1098 & 1.1854 & 1.2514 \\
7.75 & 1.0355 & 1.0851 & 1.1298 & 1.1788 \\
15.75 & 1.0316 & 1.0624 & 1.0961 & 1.1265 \\
31.75 & 1.0300 & 1.0461 & 1.0619 & 1.0806 \\
63.75 & 1.0181 & 1.0257 & 1.0349 & 1.0439 \\
\hline
\end{tabular}

than 1 depending on whether the heat transfer rate is increased or decreased, respectively, as a result of TVC.

Numerical results are obtained for the ratio $\mathrm{R}$ as a function of $\overline{\mathrm{x}}$ for $\mathrm{Pr}=0.7$ and for a few values of the TVC parameter, $\gamma$, namely, $0.25,0.5,0.75$ and 1.0, respectively. For $\operatorname{Pr}=0.7$, it is known that $\left[-g^{\prime}(0)\right]_{\text {NO-TVC }}=0.45113$

Solutions of Eqs. (16) and (17) then give $\left[-g^{\prime}(0)\right]_{\text {TVC }}$ - vs - $\overline{\mathrm{x}}$ for each value of the TVC parameter. Equation (23) can then be used to calculate the ratio $R$ as a function of $\bar{x}$. The results are summarized in Table 1 . The following conclusions are drawn:

1. For all the cases considered, the effect of TVC is to increase the rate of heat transfer. The increase can be as high as $36 \%$ for large value of the TVC parameter.

2. The ratio $R$ first increases with $x$, reaches a maximum at a certain location and then decreases with $\mathrm{x}$. This is physically reasonable since, as $\mathrm{x}$ increases, the boundary layer thickness becomes small as compared with the radius of the cone, $r_{0}$, and as a result the TVC effect becomes less important.

3 . Larger values of the TVC parameter correspond to more profound TVC effect. From the definition of $\gamma$, a large $\gamma$ means either a smaller cone angle $\alpha$ or a smaller $x_{0}$. In both cases, the boundary layer thickness becomes closer to the cone radius $r_{O}$ and an increase in the TVC effect results.

As a final remark, an example will be given to show how the solution for the frustum of a cone as presented above can be used approximately for a ful- 
cone. Consider, for example, the problem of natural convection of air at $80^{\circ} \mathrm{F}$ over the frustum of a cone $\left(\mathrm{L}=1 \mathrm{ft}, \mathrm{x}_{0}=2 \mathrm{in}\right.$. and $\left.\alpha=5^{\circ}\right)$ with surface temperature of $520^{\circ} \mathrm{F}$. For this case, the TVC parameter $\gamma$ is found to be 0.34 . If we decrease $x_{0}$ from 2 in. to 0.5 in., the corresponding value of $\gamma$ will be 0.96 . For such a small value of $\mathrm{x}_{0}$ (Fig.1), the solution for the frustum of a cone becomes a good approximation of the boundary layer flow over a full cone with $\mathrm{L}=12.5 \mathrm{in}$., especially in view of the fact that the boundary layer equations no longer apply near the tip of a full cone. It should be noted, however, that from the mathematical point of view, $x_{0}$ cannot be equal to zero since a zero value of $x_{0}$ will give rise to a mathematical singularity in the transverse curvature factor $\overline{\mathrm{r}} / \overline{\mathrm{r}}_{0}$ in the differential Equations, Eqs. (10) and (11).

\section{Literature}

1. Merk, H.J.; Prins, J.A.: Thermal Convection in Laminar Boundary Layer I. Appl. Sci. Res. 4A (1953) 11-24, 195-206

2. Hering, R.G.; Grosh, R.J. : Laminar Free Convection from a Non-Isothermal Cone. International J . of Heat and Mass Transfer 5 (1962) 10591067
3. Hering, R.G.: Laminar Free Convection from a Non-Isothermal Cone at Low Prandtl Numbers. International $\mathrm{J}$. of Heat and Mass Transfer 8 (1965) 1333-1337

4. Sparrow, E.M.; Guinle, L.D.F . : Deviations from Classical Free Convection Boundary Layer Theory at Low-Prandtl Numbers. International J of Heat and Mass Transfer 11 (1968) 1403-1415

5. Roy, S.: Free Convection from a Vertical Cone at High Prandtl Numbers. J . of Heat Transfer, Trans. ASME. 96 (1974) 115-117

6. Cebeci, T.; Qasim, J.; Na, T.Y.: Free Convective Heat Transfer from Slender Cylinders Subject to Uniform Wall Heat Flux. Letters in Heat and Mass Transfer 1 No. 2 (1974) 159-162

7. Cebeci, T.: Laminar Free Convection Heat Transfer from the Outer Surface of a Vertical Slender Circular Cylinder. Proc. of the 5th International Heat Transfer Conference 3, No. NC1.4 (1974) 15-19

8. Na, T.Y.: Numerical Solution of Natural Convection Flow Past a Non-isothermal Vertical Flat Plate. Appl. Sci. Res. 33 (1977)

T.Y. Na

University of Michigan-Dearborn

Dearborn, Michigan USA

J.P. Chiou

University of Detroit

Detroit, Michigan USA

Received April 13, 1978 